\title{
PAPER
}

\section{Probiotics: a role in the treatment of intestinal infection and inflammation?}

\author{
E Isolauri, P V Kirjavainen, S Salminen
}

Gut 2002;50(Suppl III):iii54-iii59

Probiotic therapy is based on the concept of normal healthy microflora. The development of novel means of characterising the gut microflora, in particular those based on the different levels of conservation in the ribosomal RNA sequences of different genera, have opened up new angles on the role of the gut microflora in health and disease. Components of the human intestinal microflora or organisms entering the intestine may have harmful or beneficial effects on human health. Abundant evidence implies that specific strains selected from the healthy gut microflora exhibit powerful antipathogenic and anti-inflammatory capabilities, and are consequently involved with enhanced colonisation resistance in the intestine. Realisation of this has led to the introduction of novel modes of therapeutic and prophylactic intervention based on the consumption of mono and mixed cultures of beneficial live microorganisms as probiotics.

See end of article for authors' affiliations

Correspondence to: Dr E Isolauri, Department of Paediatrics, University of Turku, 20520 Turku, Finland;

erika.isolauri@utu.fi nflammation and infection are frequently accompanied by imbalance in the intestinal microflora. A strong inflammatory response may then be mounted to microfloral bacteria, leading to perpetuation of the inflammation and gut barrier dysfunction. Probiotic bacteria may counteract the inflammatory process by stabilising the gut microbial environment and the intestine's permeability barrier, and by enhancing the degradation of enteral antigens and altering their immunogenicity. Another explanation for the gut stabilising effect could be improvement of the intestine's immunological barrier, particularly intestinal IgA responses. Probiotic effects may also be mediated via control of the balance between pro- and anti-inflammatory cytokines. Modification of intestinal flora to increase the predominance of specific non-pathogenic bacteria and thereby to alter the intestinal milieu may thus be taken as an alternative to attain prophylactic or therapeutic effects in intestinal infectious and inflammatory conditions.

\section{PROBIOTICS}

Probiotics are live microbial food supplements or components of bacteria which have been shown to have beneficial effects on human health. ${ }^{1}$ Earlier probiotics were selected mainly to provide strains with good food processing conditions. This selection has been redefined to include healthy human intestinal or mucosal microflora as the main source of new strains, with added emphasis on survival in the gut, acid and bile stability, and temporal colonisation of the mucosal surfaces in the intestinal tract. The most frequently used genera fulfilling these criteria are lactobacilli and bifidobacteria.

The application of probiotics has been supplemented with the concept of prebiotics (table 1). The most commonly used prebiotics are carbohydrate substrates with the ability to promote the components of the normal intestinal microflora which may evince a health benefit to the host. However, prebiotics can also be non-absorbable substrates which stimulate the growth of probiotics. When the two are applied together the concept is defined as synbiotic (table 1).

\section{NORMAL GUT MICROFLORA OF A HEALTHY HUMAN-A SOURCE OF PROBIOTICS}

The intestine's normal microflora ${ }^{2}$ is a metabolically active but as yet unexplored organ of host defence. Establishment of a normal flora provides the host with the most substantial antigen challenge, with a strong stimulatory effect for maturation of the gut associated lymphoid tissue. $^{3-6}$ Although bacteria are distributed throughout the intestine, the major concentration of microbes and metabolic activity is found in the large intestine. ${ }^{13}$ From culture based data it has

\begin{tabular}{|c|c|}
\hline $\begin{array}{l}\text { Normal } \\
\text { intestinal flora }\end{array}$ & $\begin{array}{l}\text { The complex collection and balance } \\
\text { of microorganisms which normally } \\
\text { inhabit the gastrointestinal tract, } \\
\text { fulfilling a role in host nutrition, } \\
\text { physiology, and control of the } \\
\text { immune system }\end{array}$ \\
\hline Probiotic & $\begin{array}{l}\text { A live microbial food ingredient } \\
\text { which is beneficial to health }\end{array}$ \\
\hline Prebiotic & $\begin{array}{l}\text { A non-digestible food ingredient } \\
\text { which beneficially affects the host } \\
\text { by selectively stimulating the growth } \\
\text { and/or activity of one or a limited } \\
\text { number of bacteria in the colon } \\
\text { having the potential to improve host } \\
\text { health }\end{array}$ \\
\hline Synbiotic & $\begin{array}{l}\text { A mixture of probiotics and } \\
\text { prebiotics which beneficially affects } \\
\text { the host by improving the survival } \\
\text { and implantation of live microbial } \\
\text { dietary supplements in the } \\
\text { gastrointestinal tract, and thus } \\
\text { improving host health and wellbeing }\end{array}$ \\
\hline
\end{tabular}


been shown that the mouth harbours a complex microflora consisting of facultative and strict anaerobes, including streptococci, bacteroides, lactobacilli, and yeasts. The upper bowel (stomach, duodenum, and jejunum) has a sparse microflora with a content of up to $10^{5}$ colony forming units $/ \mathrm{ml}$. From the ileum on, bacterial concentrations gradually increase, reaching $10^{11}$ to $10^{12}$ colony forming units/g in the colon. It has been estimated that at least 500 different microbial species exist, although on a quantitative basis 10-20 genera probably predominate in the normal human microflora, for example, Bacteroides, Lactobacillus, Clostridium, Fusobacterium, Bifidobacterium, Eubacterium, Peptococcus, Peptostreptococcus, Escherichia, and Veillonella.

Microbial colonisation commences immediately after birth. ${ }^{3}$ The maternal vaginal and intestinal flora constitutes a source of bacteria colonising intestine of the newborn. Colonisation is also determined by contact with the surrounding environment. At this stage, the dominating strains are facultative anaerobes such as the enterobacteria, coliforms, and lactobacilli.

The diet may exert a major effect on the composition and activity of the gut microflora. In infants, it is thought that those who are breast fed have a natural predominance of bifidobacteria, while formula fed infants have a profile more complex and similar to the adult microflora, with enterobacteria, lactobacilli, bacteroides, clostridia, bifidobacteria, and streptococci. ${ }^{7}$ After weaning, the composition of the microflora gradually alters to resemble that of the adult.

The indigenous bacteria have sometimes been classified as potentially harmful or health promoting; most of them, however, are part of the commensal flora. The strains with beneficial properties include principally bifidobacteria and lactobacilli. The most common probiotics (table 1) are bifidobacteria and lactobacilli, and some of these exhibit powerful antiinflammatory capabilities. ${ }^{8}$ Moreover, the same genera have been attributed with other beneficial aspects such as stimulation of the immune response and competitive exclusion of pathogens, whereby non-specific host resistance to microbial pathogens is promoted.

\section{RATIONALE OF THERAPEUTIC MODULATION OF GUT MICROECOLOGY IN INTESTINAL INFLAMMATION AND INFECTION}

The gastrointestinal barrier controls antigen transport in the gut. The integrity of the intestine's mucosal defence depends on a number of factors in both intestinal lumen and mucosa. In common, these factors restrict colonisation by pathogens, eliminate foreign antigens which have penetrated the mucosa, and regulate the antigen specific immune responses. ${ }^{9}$ In order to establish infection or inflammation, the antigen must circumvent this impressive array of intestinal defences.

Most antigens encountered are already processed when they contact the mucosal surface. Proteases of the intestinal bacteria degrade the antigenic structure, an important step in the introduction of unresponsiveness to dietary antigens. The regulatory events in the intestinal immune response take place in different intestinal lymphoid compartments: mesenteric lymph nodes, Peyer's patches, isolated lymph follicles, and isolated $\mathrm{T}$ lymphocytes in the epithelium and the lamina propria, as well as at secretory sites. The secretory IgA antibodies in the gut are part of the common mucosal immune system, which includes the respiratory tract and lacrimal, salivary, and mammary glands. Consequently, an immune response initiated in the gut associated lymphoid tissue can affect immune responses at other mucosal surfaces.

Oral tolerance consists of an immunological hyporesponsiveness to antigens encountered by the enteric route, a hallmark of gut immune regulation. ${ }^{10}$ Oral tolerance mechanisms are considered to apply not only to dietary antigens but also to the resident microflora. ${ }^{11}$ Tolerance is mediated by suppression of the lymphocyte response and clonal deletion and/or anergy in the periphery. Two specific populations of regulatory lymphocytes have been identified: regulatory $\mathrm{T}$ lymphocytes and $\mathrm{T}$ helper 3 cells. These function by production of suppressive cytokines, including interleukin 10 and transforming growth factor $\beta$, respectively. It has been suggested that one of the major mechanisms by which the gut associated lymphoid tissue maintains homoeostasis is via local cytokine regulation. This homoeostasis allows for the maintenance of tolerance to the massive antigen exposure encountered by the enteric route: oral tolerance to dietary antigens and healthy interactions between the resident gut microflora and the epithelium. The homoeostasis requires effective gut barrier functions and epithelial integrity.

The demonstration that in the absence of the intestinal microflora antigen transport is increased indicates that the gut microflora is an important constituent in the intestine's defence barrier. ${ }^{8}$ The initial compositional development of the gut microflora is considered a key determinant in the development of normal gut barrier functions. ${ }^{12}$ In affecting the development of gut associated lymphoid tissue at an early age, the gut microflora directs the regulation of systemic and local immune responsiveness, including hyporesponsiveness to antigens derived from microorganisms and food. Experimental animals lacking interleukin 10 or transforming growth factor $\beta$ generate a mucosal inflammatory response to the resident gut microflora. ${ }^{13}$ These observations mirror the complex interactions between microflora and the gut mucosal barrier.

The role of the intestinal microflora in oral tolerance induction has been investigated in germ free mice. ${ }^{5}$ In contrast to control mice, germ free animals were seen to maintain their tendency to a systemic immune response, for example production of IgE antibodies, on oral antigen administration. Abrogation of oral tolerance was a result of the absence of intestinal flora. The aberrant IgE response could be corrected by reconstitution of the microflora at the neonatal stage, but not at a later age. Recent studies following the microfloral development in vaginally born infants and in infants born by caesarean section have shown major differences in culturable microflora. ${ }^{14}$ Colonisation was associated with the maturation of humoral immune mechanisms, particularly of circulating IgA and IgM secreting cells, ${ }^{6}$ reflecting the dependency of the regulation of the mucosal immune response on the normal gut microflora.

In several gut related inflammatory conditions, the healthy host-microbe interaction is disturbed and inflammation is accompanied by imbalance in the intestinal microflora in such a way that an immune response may be induced by resident bacteria. Rotavirus diarrhoea is associated with an increased concentration of faecal urease, an inflammatory mediator which predisposes the gut mucosa to ammonia induced detrimental effects and to the overgrowth of urease producing bacteria. $^{15}$ Duchmann and associates ${ }^{11}$ have shown that healthy individuals are tolerant to their own microflora, and that such tolerance is abrogated in patients with inflammatory bowel disease. An altered gut microflora is reported in patients with rheumatoid arthritis ${ }^{16}$ and allergic disease, ${ }^{17} 18$ implying that the normal gut microflora constitutes an ecosystem responding to inflammation in the gut and elsewhere in the human body.

Preliminary data from human studies indicate a dependency on the gut microflora and on the dysregulated immune response to their antigenic structures for the development of gut associated inflammatory conditions, ranging from allergies to autoimmune and inflammatory diseases. ${ }^{19}$ Normalisation of the properties of unbalanced indigenous microflora by specific strains of the healthy gut microflora constitutes the rationale in probiotic therapy (fig 1). Oral introduction of probiotics may halt the vicious circle in inflammation (fig 2). The probiotic performance manifests itself in normalisation of the 


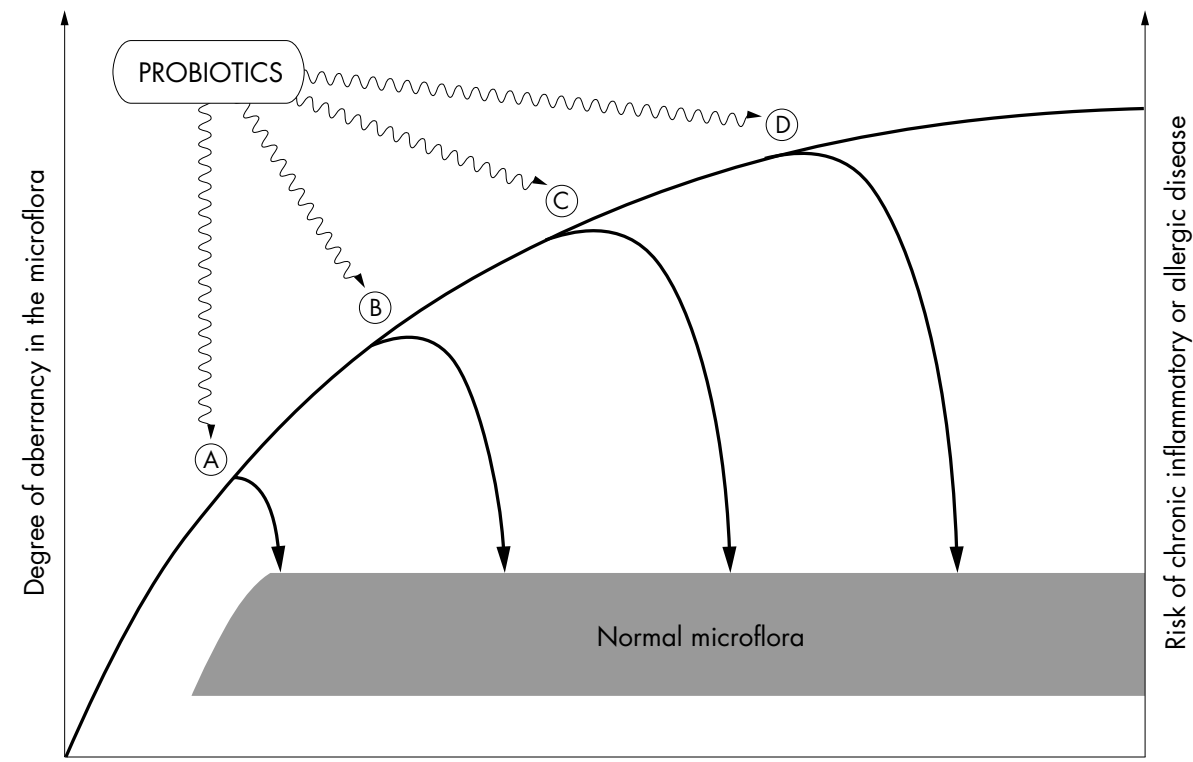

$\begin{array}{lll}\begin{array}{l}\text { A Primary exposure (B) Diet (e.g. formula feeding) } \\ \text { and genetic factors } \\ \text { and antimicrobial treatments }\end{array} & \begin{array}{l}\text { Immune responder } \\ \text { type, stress, and aging }\end{array}\end{array}$

Figure 1 Evolution of the gut microflora and the rationale of probiotic therapy. Different internal and external challenges interfere with the normal balance of the healthy gut microflora. Their effects can be reversed by specific strains of the healthy gut microflora. Normalisation of the properties of unbalanced indigenous microflora by specific strains of the healthy gut microflora forms the rationale of probiotic therapy.

increased intestinal permeability and altered gut microecology, improvement of the intestine's immunological barrier functions, and alleviation of the intestinal inflammatory response. The targets for probiotic therapy are identified as clinical conditions involving impaired mucosal barrier function, particularly infectious and inflammatory diseases.

\section{CLINICAL DEMONSTRATIONS OF PROPHYLACTIC AND THERAPEUTIC EFFECTS OF PROBIOTICS}

The potential health effects of normal gut microflora have to be shown by well controlled clinical and nutritional studies in human subjects. So far, several clinical studies have

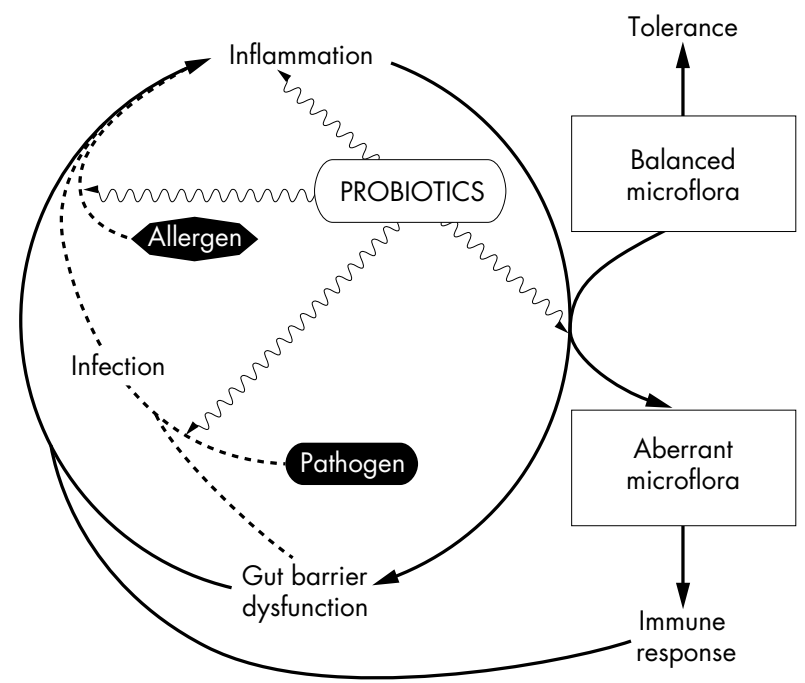

Figure 2 Gut microflora in inflammation. Inflammation may direct the composition and function of a balanced normal microflora to become aberrant and immunogenic, leading to perpetuation of the inflammation and gut barrier dysfunction. Probiotic bacteria may counteract the inflammatory process by enhancing the degradation of enteral antigens, reducing the secretion of inflammatory mediators, and promoting the normalisation of indigenous flora and the exclusion of pathogens. investigated the use of probiotics, principally lactobacilli and bifidobacteria, as dietary supplements for the prevention and treatment of various gastrointestinal infectious and inflammatory conditions.

\section{Acute gastroenteritis}

The most fully studied gastrointestinal condition treated by probiotics is acute infantile diarrhoea. In patients hospitalised for acute rotavirus diarrhoea, Lactobacillus strain GG (ATCC 53103) as fermented milk or as freeze dried powder, significantly reduced the duration of diarrhoea compared to a placebo group given pasteurised yoghurt. ${ }^{20}$ The result has since been confirmed in studies carried out in a similar population ${ }^{21}$ as well as in different populations. ${ }^{22}$ The effect has been explained by stabilisation of the indigenous microflora, ${ }^{15}$ reduction in the duration of rotavirus shedding, ${ }^{23}$ and reduction in increased gut permeability caused by rotavirus infection, ${ }^{24}$ together with a significant increase in IgA secreting cells to rotavirus. ${ }^{2125}$

A multicentre study by the European Society for Paediatric Gastroenterology, Hepatology, and Nutrition working group tested the clinical efficacy of probiotics in cases of acute diarrhoea caused by rotavirus or other pathogens. ${ }^{26}$ In rotavirus diarrhoea, a significant shortening in the duration of diarrhoea was observed, while in non-specific or bacterial diarrhoea no clear effect was found. The study showed the safety of administration of a probiotic in an oral rehydration solution and prevention of the evolution of rotavirus diarrhoea towards a protracted course.

Probiotics have been also shown to be effective in the prevention of acute infantile diarrhoea. Saavedra and colleagues ${ }^{27}$ conducted a double blind, placebo controlled trial in hospitalised infants who were randomised to receive a standard infant formula or the same formula supplemented with Bifidobacterium bifidum (later renamed Bifidobacterium lactis) and Streptococcus thermophilus. During a 17 month follow up, $31 \%$ of the patients given the standard infant formula, but only $7 \%$ of those receiving the probiotic supplemented formula developed diarrhoea; the prevalence of rotavirus shedding was significantly lower in those receiving the probiotic supplemented formula. Probiotic supplementation 
resulted in a significant decrease in the incidence of diarrhoea in undernourished Peruvian children followed up for 15 months. ${ }^{28}$ The effect was, however, confined to non-breastfed children. More recently, a group under Szajewska evaluated the efficacy of orally administered Lactobacillus GG in the prevention of nosocomial diarrhoea in young children. ${ }^{29}$ Eighty one children aged 1-36 months, who were hospitalised for reasons other than diarrhoea, were enrolled in a randomised, double blind trial to receive probiotics or placebo for the duration of their hospital stay. Lactobacillus GG reduced the incidence of nosocomial diarrhoea in comparison with placebo $(6.7 \%$ versus $33.3 \%$; relative risk $0.2,95 \%$ CI 0.06 to $0.6)$. The prevalence of rotavirus infection was similar in probiotic and placebo groups. However, the use of probiotics compared with placebo significantly reduced the risk of rotavirus gastroenteritis, suggesting that probiotics reduce the risk of nosocomial diarrhoea in infants.

\section{Inflammatory bowel disease}

Ingestion of probiotic bacteria has the potential to stabilise the immunological barrier in the gut mucosa by reducing the generation of local proinflammatory cytokines (fig 2). Preliminary reports have shown clinical benefit in reversing some of the immunological disturbances characteristic of Crohn's disease.$^{30}$ Most evidence for a role of aberrant gut microflora in inflammatory bowel disease, however, derives from experimental animal models. Transgenic mice with targeted deletion of the T cell receptor (TCR $\alpha$ ) spontaneously develop colitis in response to the gut microflora. ${ }^{31}$ If organised gut associated lymphoid tissue is removed from the mice by appendicectomy at neonatal age, but not later, tolerance to gut microflora develops and the mice do not develop colitis, indicating that the initial colonisation pattern may determine subsequent immunological processes. Numerous experimental studies have indeed shown that the lack or inadequacy of maturational signals from the gut microflora results in decreased intestinal surface area, altered mucosal enzyme patterns, defects in the non-immunological barrier of the intestine, reduced capacity for inflammatory responses, a defective mucosal IgA system, and abrogation of oral tolerance. ${ }^{1-632} 33$ The limited availability of controlled data in human inflammatory disease calls for more research on the effects of specific probiotic strains on the distinct forms of inflammatory bowel disease and its complications.

\section{Allergic disease}

The prevalence of atopic diseases has been progressively increasing in Western societies. The hygiene hypothesis of allergy conceives the rapid increase in atopy to be related to reduced exposure to microbes at an early age. ${ }^{34}$ The earliest and most massive source of such exposure is associated with the establishment of the gut microflora. The regulatory role of probiotics in human allergic disease was first emphasised in the demonstration of a suppressive effect on lymphocyte proliferation and interleukin 4 generation in vitro. ${ }^{35}{ }^{36}$ Subsequently, the immunoinflammatory responses to dietary antigens in allergic individuals were shown to be alleviated by probiotics, this being partly attributable to enhanced production of the anti-inflammatory cytokines interleukin $10^{37}$ and transforming growth factor $\beta,{ }^{38}$ and partly to control of allergic inflammation in the gut. ${ }^{39}$

In one prospective study, intestinal microflora from 76 infants at high risk of atopic disease were analysed at 3 weeks and 3 months of age by conventional bacterial cultivation and two culture independent methods, gas-liquid chromatography of bacterial cellular fatty acids and quantitative fluorescence in situ hybridisation of bacterial cells. ${ }^{40}$ Positive skin prick reaction at 12 months was observed in 22/76 (29\%) children. At 3 weeks of age the bacterial cellular fatty acid profile in faecal samples differed significantly between infants developing and not developing atopy $(\mathrm{p}=0.005)$. On fluorescence, in situ hydridisation atopics were found to have more clostridia and tended to have fewer bifidobacteria in their stools than non-atopics. Differences in the neonatal gut microflora were thus shown to precede the development of atopy, suggesting a crucial role of the balance of indigenous intestinal bacteria for the maturation of human immunity to a non-atopic mode.

A significant improvement in the clinical course of atopic eczema has been observed in infants given a probiotic supplemented diet, and in parallel, markers of systemic ${ }^{38}$ and intestinal ${ }^{39}$ allergic inflammation were significantly decreased. Similar results have been obtained in milk hypersensitive adults. ${ }^{41}$ In these subjects, a milk challenge in conjunction with a probiotic strain prevented the immunoinflammatory response characteristic of the response without probiotics.

The preventive potential of probiotics in atopic disease has recently been shown in a double blind, placebo controlled study. ${ }^{42}$ Probiotics administered pre- and postnatally for six months to children at high risk of atopic diseases succeeded in reducing the prevalence of atopic eczema to half compared with that in infants receiving placebo.

\section{PROBIOTIC THERAPY: REQUIREMENTS FOR SPECIFIC STRAINS}

The role of the diet in health and wellbeing has changed as the science of nutrition has evolved. Research interest is currently directed towards improvement of defined physiological functions beyond the nutritional impact of food, including the potential to reduce the risk of disease. This is also the focus for probiotic research. The future probiotics will have more thoroughly clarified mechanisms to either control specific physiological processes in the evolution of disease in at-risk populations or in the dietary management of specific diseases. Probiotic functional foods can be defined as products containing specific probiotic microbes with scientifically proven clinical efficacy for the final product intended for human use. The development of probiotic functional foods requires new criteria for strains appropriate to specific indications.

The prerequisites for probiotic action include survival in and adhesion to specific areas of the gastrointestinal tract and competitive exclusion of pathogens or harmful antigens. These processes may depend firstly on specific strain characteristics, and secondly on the age and the immunological state of the host. Some probiotic strains adhere better to the small intestine, while some bind specifically to different parts of the large intestine. ${ }^{43}$ It is likely that strains also adhere differently in healthy versus damaged mucosa. ${ }^{44}$ Moreover, even closely related probiotics have been shown to possess different in vitro properties, ${ }^{45}$ possibly also explaining differences in clinical effects. ${ }^{21}$ However, it has recently been shown that strains with lower total in vitro binding capacity may still effect high competitive exclusion of pathogens or harmful bacteria ${ }^{46}$ indicating a need for further characterisation of adhesion properties to develop preclinical selection methodologies for candidate probiotic strains.

Probiotic fulfilment may also arise from the use of genetically modified bacteria evincing improved or added functional properties. These include probiotics engineered to produce anti-inflammatory cytokines. Reports on the effects of Lactococcus lactis engineered to produce interleukin 10 locally in the mouse intestinal mucosa point to a strong potential for future therapeutic applications. ${ }^{47}$ Other methods of probiotic modification are exposure of the microorganism to sublethal stress, such as acidic conditions or heat, in order to improve survival in the gastrointestinal tract and improve tolerance to stress, and thereby to furnish the organism with improved competitiveness against pathogens in the intestinal milieu. ${ }^{48-50}$ Inactivation might also have a potential in the modification of probiotics. The use of inactivated instead of viable microorganisms would have its merits in terms of 
safety, longer shelf life, and less interaction with other components of the food product. In general, inactivated probiotics have been studied clinically to a lesser degree than their viable counterparts. In the treatment of rotavirus diarrhoea, inactivated probiotics have been shown to be as effective as the active in shortening the duration of diarrhoea episodes, but their ability to stimulate the host immune defence was weaker. ${ }^{21}$ The same appears to apply to bacterial infections, as indicated in studies exposing mice to Salmonella typhimurium ${ }^{51}$; only viable probiotics stimulated the antigen specific immune response. However, in some cases such as intestinal toxin binding, non-viable probiotics may even be more effective than the viable ones. ${ }^{52}$

\section{SAFETY ASPECTS OF PROBIOTIC THERAPY}

Modification of the gut microflora forms a relatively new treatment modality for gastrointestinal disorders. Probiotic therapy with demonstrated health effects is a novel approach. The ingestion of large numbers of viable bacteria requires assurance of safety. The probiotics currently used have been assessed as safe for use in fermented foods, but generally the safety assessment of microbial food supplements is not well developed. ${ }^{23}$

Some studies have suggested the gut as an origin of disease caused by bacteria normally residing in the intestinal lumen but occasionally translocating across the intestinal epithelium.$^{54}$ As more adhesive strains have been selected for probiotic use, the ability to survive in gastric conditions and to adhere to the intestinal epithelium may entail a risk of translocation. ${ }^{55}$ Translocation may be enhanced by gut barrier dysfunction caused by inflammation. Effective probiotics may, however, possess properties which counteract epithelial damage and consequently reduce the risk of translocation. The concept of translocation implies specific safety requirements for microbes used in oral bacteriotherapy. Among these are the origin of the strain, its species characteristics, and its stability. An acceptable origin is the normal healthy human intestinal microflora.

Probiotics have been selected from members of the normal healthy intestinal microflora, most of them belonging to Lactobacillus or Bifidobacterium, but new probiotic microbes from other species and genera have recently been introduced. Bifidobacteria and lactic acid bacteria have rarely caused disease through translocation and their safety record in fermented milk, vegetables, and cereals is excellent. Their natural presence on all human mucosal surfaces also attests to their safety.

Genetically modified microorganisms are not currently used or planned for use in foods. The rapid development in this area, however, may change their application targets. The most important safety concern is the content of antibiotic resistance markers in the genetic constituents of modified organisms. Selection procedures have been developed to ensure the absence of such markers specifically for lactococci. $^{52}$ In the case of the new probiotics, use of inactivated bacteria has been proposed, partly as their consumption appears to be safer than the use of viable bacteria. However, information on the effects of inactivation methods on the cell wall structure and composition is scarce. For example, heat treatment methods are likely to induce a number of changes on the cell wall structures of sensitive probiotics, thus consequently influencing for example the immunogenicity and the adhesion properties of these agents. Such concerns limited to heat treatment; detrimental effects may also be expected, for example, in response to lyophilisation and other technological treatments.

Taken together, the influence and long term effects of traditional and new probiotics on the resident gut microflora and their metabolic activity should be characterised in well defined surveillance studies. These should include characterisation of the specific immunomodulatory properties of strains for the development of specific clinical applications in defined target populations.

\section{CONCLUSIONS}

Probiotics are live microbial food supplements or components of bacteria which have been shown to have beneficial effects on human health. Recent research has expanded the definition of probiotics, as it has been shown that genetically engineered microbes and non-viable microbes may equally possess such potential. However, normalisation of the properties of unbalanced indigenous microflora by specific strains of the healthy gut microflora forms the rationale of probiotic therapy. Oral introduction of probiotics has been shown to reinforce the various lines of gut defence: immune exclusion, immune elimination, and immune regulation. Probiotics also stimulate non-specific host resistance to microbial pathogens and thereby aid in their eradication. The application of probiotics currently lies in reducing the risk of diseases associated with gut barrier dysfunction. The probiotic performance of strains differs; different bacteria or modifications/components thereof have defined adherence sites, immunological effects, and varied effects in the healthy versus inflamed mucosal milieu. In the future, such specific probiotic properties might be exploited in the development of disease specific prophylactic and therapeutic interventions.

\section{Authors' affiliations}

E Isolauri, Department of Paediatrics, University of Turku, Finland P V Kirjavainen, S Salminen, Department of Biochemistry and Food Chemistry, University of Turku

\section{REFERENCES}

1 Salminen S, Bouley C, Boutron-Ruault MC, et al. Gastrointestinal physiology and function-targets for functional food development. $\mathrm{Br} J$ Nutr 1998:80(suppl):147-71.

2 Berg RD. The indigenous gastrointestinal microflora. Trends Microbiol 1996;4:430-5

3 Benno Y, Mitsuoka T. Development of intestinal microflora in humans and animals. Bifidobacteria Microfi 1986;5:13-25.

4 Cebra JJ. Influences of microbiota on intestinal immune system development. Am J Clin Nutr 1999;69(suppl):1046-51.

5 Sudo N, Sawamura S, Tanaka K, et al. The requirement of intestinal bacterial flora for the development of an lgE production system fully susceptible to oral tolerance induction. J Immunol 1997; 159:1739-45.

6 Grönlund MM, Arvilommi H, Kero P, et al. Importance of intestinal colonisation in the maturation of humoral immunity in early infancy: a prospective follow up study of healthy infants aged 0-6 months. Arch Dis Child Fetal Neonatal Ed 2000;83:F186-92.

7 Harmsen HJ, Wildeboer-Veloo AC, Raangs GC, et al. Analysis of intestinal flora development in breast-fed and formula-fed infants by using molecular identification and detection methods. J Pediatr Gastroenterol Nutr 2000;30:61-7.

8 Isolauri $E$, Sütas $Y$, Kankaanpää $P$, et al. Probiotics: effects on immunity. Am J Clin Nutr 2001;73:S444-50.

9 Sanderson IR, Walker WA. Uptake and transport of macromolecules by the intestine: possible role in clinical disorders (an update). Gastroenterology 1993;104:622-39.

10 Weiner HL, van Rees EP. Mucosal tolerance. Immunol Lett 1999:69:3-4

11 Duchmann R, Kaiser I, Hermann E, et al. Tolerance exists towards resident intestinal flora but is broken in active inflammatory bowel disease (IBD). Clin Exp Immunol 1995; 102:448-55.

12 Hooper LV, Wong MH, Thelin A, et al. Molecular analysis of commensal host-microbial relationships in the intestine. Science 2001;291:881-4.

13 Groux H, Powrie F. Regulatory T cells and inflammatory bowel disease. Immunol Today 1999;20:442-6.

14 Grönlund MM, Lehtonen OP, Eerola E, et al. Fecal microflora in healthy infants born by different methods of delivery: permanent changes in intestinal flora after cesarean delivery. J Pediatr Gastroenterol Nutr 1999;28:19-25.

15 Isolauri E, Kaila $M$, Mykkänen $H$, et al. Oral bacteriotherapy for viral gastroenteritis. Dig Dis Sci 1994;39:2595-600.

16 Malin M, Verronen P, Mykkänen H, et al. Increased bacterial urease activity in faeces in juvenile chronic arthritis: evidence of altered intestinal microflora? Br J Rheumatol 1996;35:689-94. 
17 Apostolou E, Pelto L, Kirjavainen PV, et al. Differences in the gut bacterial flora of healthy and milk-hypersensitive adults, as measured by fluorescence in situ hybridisation. FEMS Immunol Med Microbiol 2001;30:217-21.

18 Biörkstén B, Naaber P, Sepp E, et al. The intestinal microflora in allergic Estonian and Swedish 2-year-old children. Clin Exp Allergy 1999;29:342-6.

19 Isolauri E. Probiotics in human disease. Am J Clin Nutr 2001;73: 11425-65

20 Isolauri $\mathbf{E}$, Juntunen $M$, Rautanen $T$, et al. A human Lactobacillus strain (Lactobacillus GG) promotes recovery from acute diarrhea in children. Pediatrics 1991;88:90-7.

21 Majamaa $\mathbf{H}$, Isolauri E, Saxelin M, et al. Lactic acid bacteria in the treatment of acute rotavirus gastroenteritis. J Pediatr Gastroenterol Nutr 1995:20:333-9.

22 Pant AR, Graham SM, Allen SJ, et al. Lactobacillus GG and acute diarrhoea in young children in the tropics. J Trop Pediatr 1996;42: 162-5.

23 Guarino A, Canani RB, Spagnuolo MI, et al. Oral bacterial therapy reduces the duration of symptoms and of viral excretion in children with mild diarrhea. J Pediatr Gastroenterol Nutr 1997;25:516-19.

24 Isolauri E, Kaila M, Arvola T, et al. Diet during rotavirus enteritis affects jejunal permeability to macromolecules in suckling rats. Pediatr Res 1993;33:548-53.

25 Kaila $M$, Isolauri E, Soppi E, et al. Enhancement of the circulating antibody secreting cell response in human diarrhea by a human lactobacillus strain. Pediatr Res 1992;32:141-4.

26 Guandalini S, Pensabene L, Zikri MA, et al. Lactobacillus GG administered in oral rehydration solution to children with acute diarrhoea: a multicenter European trial. J Pediatr Gastroenterol Nutr 2000;30:54-60.

27 Saavedra JM, Bauman NA, Oung I, et al. Feeding of Bifidobacterium bifidum and Streptococcus thermophilus to infants in hospital for prevention of diarrhoea and shedding of rotavirus. Lancet 1994:344:1046-9.

28 Oberhelman RA, Gilman RH, Sheen P, et al. A placebo-controlled trial of Lactobacillus GG to prevent diarrhea in undernourished Peruvian children. J Pediatr 1999;134:15-20.

29 Szajewska H, Kotowska M, Mrukowicz JZ, et al. Efficacy of Lactobacillus GG in prevention of nosocomial diarrhea in infants. J Pediatr 2001;138:361-5.

30 Malin M, Suomalainen $H$, Saxelin $M$, et al. Promotion of $\lg A$ immune response in patients with Crohn's disease by oral bacteriotherapy with Lactobacillus GG. Ann Nutr Metab 1996;40:137-45.

31 Mombaerts P, Mizoguchi E, Grusby M, et al. Spontaneous development of inflammatory bowel disease in T cell receptor mutant mice. Cell 1993;75:275-82.

32 Brandtzaeg P. Development of the mucosal immune system in humans. In: Bindels JG, Goedhart AC, Visser HKA, eds. Recent developments in infant nutrition. UK: Kluwer Academic Publishers, 1996:349-76.

33 Gaskins HR. Immunological aspects of host/microbiota interactions at the intestinal epithelium. In: Mackie RI, White BA, Isaacson RE, eds. Gastrointestinal microbiology. New York: International Thomson Publishing; 1997:537-87.

34 Strachan DP. Hay fever, hygiene, and household size. BM 1989;299:1259-60

35 Sütas Y, Soppi E, Korhonen H, et al. Suppression of lymphocyte proliferation in vitro by bovine caseins hydrolysed with Lactobacillus GG-derived enzymes. J Allergy Clin Immunol 1996;98:216-24.
36 Sütas $Y$, Hurme $M$, Isolauri $E$. Downregulation of antiCD3 antibody-induced IL-4 production by bovine caseins hydrolysed with Lactobacillus GG-derived enzymes. Scand J Immunol 1996;43:687-9

37 Pessi T, Sütas $Y$, Hurme $M$, et al. Interleukin-10 generation in atopic children following oral Lactobacillus rhamnosus GG. Clin Exp Allergy 2000;30: 1804-8.

38 Isolauri E, Arvola T, Sütas Y, et al. Probiotics in the management of atopic eczema. Clin Exp Allergy 2000;30:1605-10.

39 Majamaa H, Isolauri E. Probiotics: a novel approach in the management of food allergy. J Allergy Clin Immunol 1997;99:179-86.

40 Kalliomäki M, Kirjavainen P, Eerola $E$, et al. Distinct patterns of neonatal gut microflora in infants in whom atopy was and was no developing. J Allergy Clin Immunol 2001;107:129-34.

41 Pelto L, Isolauri E, Lilius EM, et al. Probiotic bacteria downregulate the milk-induced inflammatory response in milk-hypersensitive subjects but have an immunostimulatory effect in healthy subjects. Clin Exp Allergy 1998;28:1474-9.

42 Kalliomäki $M$, Salminen S, Kero $P$, et al. Probiotics in primary prevention of atopic disease: a randomised placebo-controlled trial. Lancet 2001;357:1076-9.

43 Jin L, Marquart R, Zhao X. A strain of Enterococcus faecium (18C23) inhibits the adhesion of enterotoxigenic Escerichia coli K88 to porcine small intestinal mucus. Appl Environ Microbiol 2000;66:4200-4.

44 Mao Y, Nobaek S, Kasravi B, et al. Effects of Lactobacillus strains and oat bran on methotrexate-induced enterocolitis in rats. Gastroenterology $1996 ; 111: 334-44$

45 Ouwehand AC, Kirjavainen PV, Grönlund MM, et al. Adhesion of probiotic microorganisms to intestinal mucus. Int Dairy J 1999;9:623-30.

46 Lee YK, Lim CY, Teng WL, et al. Qualitative approach in the study of adhesion of lactic avid bacteria on intestinal cells and their competition with enterobacteria. Appl Environ Microbiol 2000;66:3692-7.

47 Steidler L, Hans W, Schotte L, et al. Treatment of murine colitis by Lactococcus lactis secreting interleukin-10. Science 2000;289: 1352-5.

48 Hartke A, Bouché S, Giard JC, et al. The lactic acid stress response to Lactococcus lactis subsp. lactis. Curr Microbiol 1996;33:194-9.

49 Hartke A, Bouché S, Gansel X, et al. Starvation-induced stress resistance in Lactococcus lactis subsp. lactis IL 1403. Appl Environ Microbiol 1994;60:3474-8.

50 Kets EPW, Teunissen PJM, de Bont JAM. Effect of compatible solutes on survival of lactic acid bacteria subjected to drying. Appl Environ Microbiol 1996;62:259-61.

51 Perdigón G, Alvarez S, Gobbato N, et al. Comparative effect of the adjuvant capacity of Lactobacillus casei and lipopolysaccharide on the intestinal secretory antibody response and resistance to salmonella infection in mice. Food Agric Immunol 1995;7:283-94.

52 El-Nezami H, Kankaanpää P, Salminen S, et al. Physico-chemical alterations enhance the ability of dairy strains of lactic acid bacteria to remove aflatoxin from contaminated media. J Food Protect 1998:61:466-8.

53 Salminen S, von Wright A, Morelli L, et al. Demonstration of safety of probiotics - a review. Int J Food Microbiol 1998;44:93-106.

54 MacFie J, O'Boyle C, Mitchell C, et al. Gut origin of sepsis: a prospective study investigating associations between bacteria translocation, gastric microflora, and septic morbidity. Gut 1999:45:223-8

55 Apostolou E, Kirjavainen, Saxelin M, et al. Good adhesion properties of probiotics: a potential risk for bacteremia? FEMS Immunol Med Microbiol. In press. 